\title{
Factors Influencing Willingness to Comply with Public Health Measures for COVID-19 Among Incoming Air Travelers Into Nigeria from High-Risk Countries: A Cross-Sectional Analysis
}

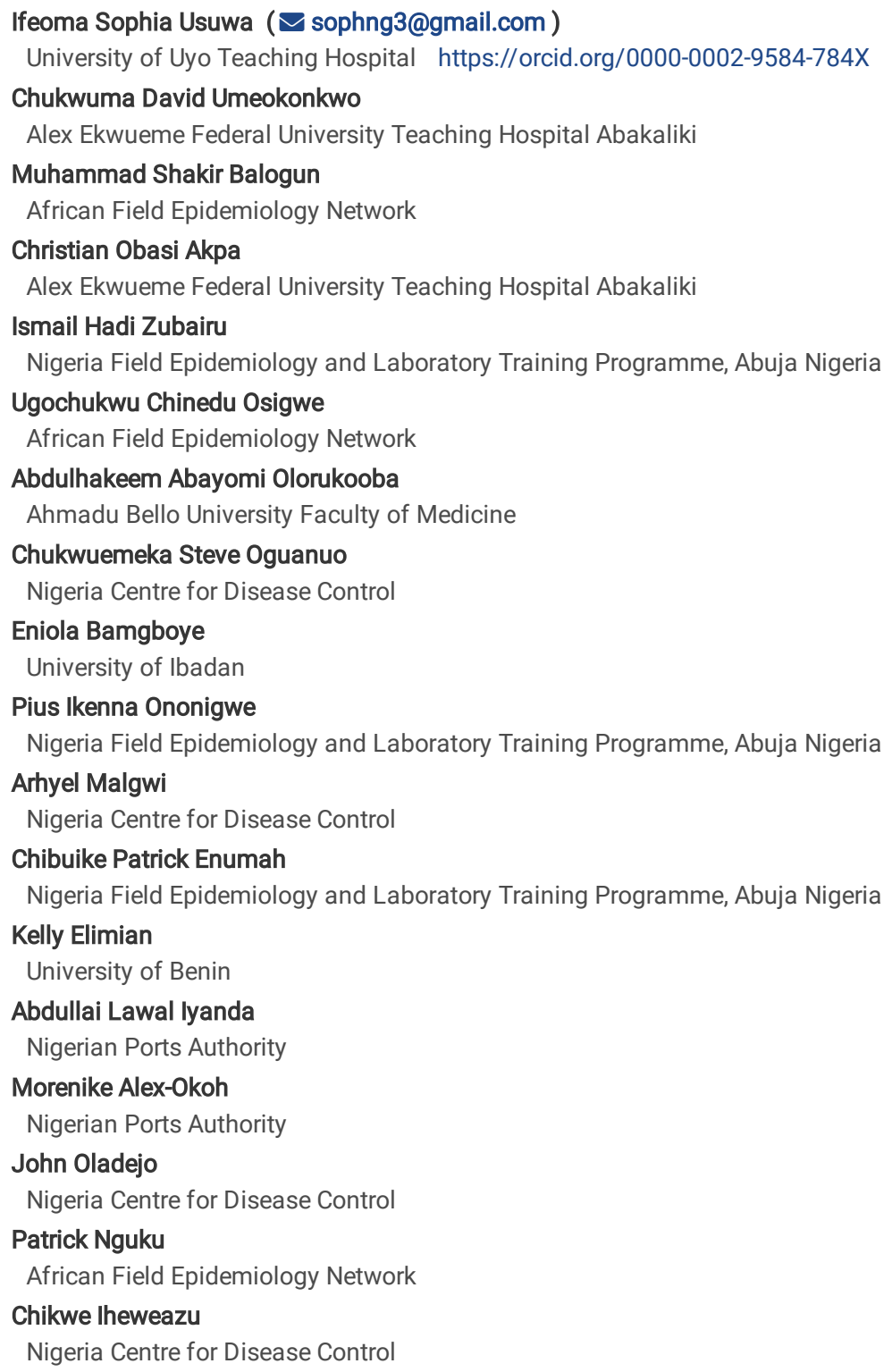




\section{Abstract}

Background: Complying with guidelines established to control COVID-19 pandemic is critical to the successful outcome of the response. We assessed the willingness of non-symptomatic incoming international air travelers into Nigeria to comply with COVID-19 public health measures upon arrival and identified the factors influencing them- March 2020.

Method: We conducted a cross-sectional study among 500 incoming international air travelers involving 17 nationals across four major international airports in Nigeria using a pre-tested self-administered electronic questionnaire. We estimated the proportions and determined predictors of participants' willingness to comply with the COVID-19 preventive measures. Predictors were examined using multiple logistic regression at $5 \%$ level of significance.

Results: Majority (83\%) were extremely/very willing to comply with public health guidelines. Perception of severity was a significant predictor of their willingness to stay at home for 14 days upon arrival (AOR: 6.82, $95 \mathrm{Cl} \%$ : 1.19-24.45). Self -efficacy towards observing self for COVID-19 symptoms was a significant predictor of willingness to observe self for symptoms (AOR: $6.82,95 \% \mathrm{Cl}: 1.19-24.45)$, and willingness to call of national COVID-19 numbers if symptoms develop (AOR: 6.82, 95\% Cl: 1.19-24.45).

Conclusion: There is a need to improve risk communication interventions against COVID-19 for international air travelers particularly enhancing self-efficacy to improve their compliance to public health measures

\section{Introduction}

International travel is a known driver of COVID-19 pandemic across the globe. ${ }^{1-3}$ Though it was first reported in Wuhan China, it was no surprise that the outbreak rapidly spread to other cities and countries around the world as Wuhan Airport had non-stop passenger flights scheduled to 113 destinations in 22 countries across the world as well as 78 domestic flights in addition to other high air traffic airports in nearby cities. ${ }^{2,4-6}$ Although the World Health Organization (WHO) declared the novel corona virus a Public Health Emergency of International Concern (PHEIC) in January 2020, no trade or travel restrictions were recommended. ${ }^{7-9}$ However, WHO recommended that countries put in place strong measures to detect the disease early, isolate and treat cases, trace contacts and promote social distancing measures commensurate with the risk. ${ }^{7,9}$ To limit the international spread of COVID-19, several countries set up point of entry surveillance mechanisms to limit the spread of COVID-19 in line with WHO's recommendations, most of which required the cooperation of the international traveler to comply with the public health measure as major outbreaks have been known to occur as a result of the late identification by the surveillance system. ${ }^{3}$ Therefore, the willingness of international travellers to comply with public health measures against the international spread of COVID-19 is of great global public health importance as international travellers could be potential carriers of the infection resulting in a propagation of the ongoing pandemic. ${ }^{9}$ As with other behaviours, in-coming air passengers' willingness to comply to these public health measures can be influenced by several factors such as their knowledge of the disease, attitude as well as perceptions. ${ }^{10-12}$ Previous research has shown that willingness of the general public to comply with public health prevention measures is essential for success in disease response and containment. ${ }^{13}$ Estimation of population compliance with such measures is valuable in assessing the effectiveness of pandemic control decisions and policies in terms of disease containment and cost. ${ }^{13} \mathrm{~A}$ systematic review of physical interventions to reduce the spread of respiratory illnesses showed a clear significant benefit of using low-cost interventions such as hand washing and wearing face masks. ${ }^{14}$ Willingness to adopt protective behaviors, have been found to be influenced by several factors including risk perception, ${ }^{15}$ anxiety, ${ }^{15}$ concern for family/children/self, ${ }^{16}$ greater knowledge concerning transmission, ${ }^{17}$ perceived effectiveness of the protective measures ${ }^{16}$, perceived susceptibility ${ }^{18}$ as well as socio-demographic characteristics. ${ }^{15,16}$.

As part of the Nigeria's coordinated efforts to contain the spread of the pandemic, the Federal Ministry of Health, through its Port Health Services Division, which is responsible for Border Health security at Points of Entry (Airports, Seaports and Ground crossings), put up measures to prevent importation and spread of the disease into the country. ${ }^{7}$ This was because of Nigeria's high turn-over of international travel. ${ }^{19,20}$. In addition to Port Health officers who are primarily stationed at these Points of Entry (POE), surge capacity health personnel were trained and deployed to POEs for international air travelers at the four major international airports in the country. ${ }^{21}$ They were tasked with the responsibility of screening all air travelers coming into the country via these points of entry. From the beginning of the pandemic, all travelers into Nigeria especially from countries with confirmed on-going community transmission of SARS-CoV2, at POEs (international airports), were screened to detect suspected cases of SARS-CoV-2. ${ }^{7}$ Health declaration forms were used to screen the arriving passengers and information obtained included travel history, history of recent illness (within the past 14 days) including fever, cough, flu-like symptoms, difficulty in breathing, history of contact with a confirmed case of COVID-19, history of visit to a health facility where a confirmed positive case was managed, and non-contact temperature monitoring devices like infrared thermometers and thermal scanners were used to detect fever. Initially, the high-risk countries (from countries with confirmed on-going community transmission of SARS-CoV-2) were China, Iran, Republic of Korea, Italy, and Japan. However, as the infection spread to more regions of the world, more countries were added to the list including France, Germany, Spain, Switzerland, U.S.A, U.K, Belgium, Norway and Netherlands. Currently, all travelers into Nigeria irrespective of country of travel origin, are screened on arrival.

All suspected cases of SARS-CoV-2 infections ${ }^{22}$ were further evaluated and tested to confirm their status. All in-coming air travelers from countries with confirmed on-going community transmission of SARS-CoV-2 were categorized as persons of interest (POI) by the NCDC. The NCDC recommended that asymptomatic POIs, self-isolate themselves by staying at home and limiting their contact with other people for 14 days, monitor themselves for symptoms of SARS-CoV-2 and report immediately if they observe symptoms by calling specific numbers designated for SARS-CoV-2 surveillance within the first 14 days of their arrival. ${ }^{7}$ This was in addition to them practicing basic precautionary measures such as frequent hand washing with soap under running water, covering mouth and nose with handkerchief or tissue paper when sneezing and or coughing (or into the elbow if a handkerchief is not available, avoiding close contact with anyone showing symptoms of respiratory illness (such as coughing and sneezing) as well as avoiding self-medication. ${ }^{7,8,23,24}$ 
Because an understanding of the characteristics of international passengers travelling in the middle of an outbreak can aid in identification of some special risks and strategies required to tackle issues of spread across countries, we assessed the willingness of non-symptomatic incoming international air travelers to comply with preventive public health strategies against SARS-CoV-2 infection in Nigeria and determined factors influencing their willingness to comply.

\section{Materials And Methods}

Study Setting

The study was conducted at four major international airports in Nigeria: Nnamdi Azikiwe International Airport (NAIA), Abuja; Mallam Aminu Kano International Airport (MAKIA), Kano State; Murtala Muhammed International Airport (MMIA), Lagos State and Port Harcourt International Airport (PHIA), Rivers State from Epi-week 11 to 14 . These airports were selected because they were designated to be the only points of entry (POE) for international air travel into the country, as part of the country's heightened surveillance against SARS-CoV2 before the country's closure of all international airports to non-emergency and nonessential international air travel in Epi-week 14. MMIA and PHIA are located in Southern Nigeria, MAKIA in Northern Nigeria, while NAIA is located in the nation's capital, in the heart of the country. (Figure 1). All four airports received flights from China in addition to other countries around the world.

The Port Health Services (PHS) Officers supported by residents and graduates of the Nigeria Field Epidemiology and Laboratory Training Program (NFELTP), staff of the NCDC and surge staff from state governments, screened all in-coming international air passengers especially those from countries with on-going community transmission of SARS-CoV-2 for symptoms of COVID-19 and history of contact. Non-symptomatic travellers from high-risk countries were categorized as persons of interest (POI). These POIs were advised to self-isolate for 14 days in addition to practising COVID-19 preventive measures. ${ }^{7}$ Symptomatic POls were further evaluated to assess if they met the suspected case definition of SARS-CoV-2 and if they did, were tested to confirm their status. Persons of interest who did not meet the suspect case definition of COVID-19 were advised to self-isolate for 14 days as well as adhere to other recommendations by the NCDC. 7,8,23,24 These POIs were monitored through calls by the NCDC for COVID-19 symptoms.

Study design, study population, and sampling technique

This was a cross-sectional study in which participants were recruited prospectively. We included all adult passengers aged 18 years and above who had been categorised as POIs in the ongoing COVID-19 airport surveillance (all in-coming air travellers from countries with confirmed ongoing community transmission of SARS-CoV-2, all in-coming air travellers who have symptoms suggestive of SARS-CoV-2 and all in-coming air travellers who are febrile upon arrival) arriving by air through one of the designated airports. All symptomatic POls were excluded from the study. The sample size was estimated using the using the Kish's formula, ${ }^{25}$

$$
n=\frac{Z_{\alpha}^{2} p q}{d^{2}}
$$

Where $\mathrm{n}=$ minimum sample size, $\mathrm{Za}=$ The standard normal deviate set at 1.96 which corresponds to $95 \%$ confidence interval, $\mathrm{p}=$ The prevalence of willingness to adhere to public health preventive measure in incoming travellers from literature is $48 \%,{ }^{13} q=1-p, d=$ Precision which at $95 \%$ Confidence interval is $5 \%$, with $n$ approximately 384 respondents. After adjusting for a non-response rate of $35 \%,{ }^{13}$ sample size was adjusted to 591 . This was proportionately allocated to the four airports based on the relative volume of international passengers per airport. ${ }^{19}$ Each airport was allocated as follows: PHIA international wing: 17, MAIKA international wing: 23, NAIA international wing: 130, MMIA international wing: 421 respondents.

Study tool

A pre-tested semi-structured, self-administered electronic questionnaire created by the authors based on available literature on COVID-19 was used to collect information from the study participants. This questionnaire was created using the google form platform and hyperlinks shared to respondents through short message services (SMS), WhatsApp, or emails based on the preference of the POls. Asymptomatic POls were consecutively recruited, and hyperlinks sent until required number of responses was attained. The questionnaire consisted of sections on socio-demographic characteristics, recent travel itinerary, previous history of contact, knowledge of novel coronavirus symptoms and preventive practises, previous practise of COVID-19 preventive health measures, risk perception towards COVID-19 (perceived severity of COVID-19, perceived susceptibility to COVID-19, and perceived self-efficacy towards these preventive measures), self-rated health status and their willingness to practise certain public health preventive health measures within 14 days of arrival (self-observation for COVID-19 symptoms, early reporting of COVID-19 symptoms if observed by calling the NCDC national emergency numbers on COVID-19, staying at home, avoidance of contact with others, covering of nose and mouth if symptomatic) as well as perceived concerns regarding the preventive measures. The questionnaire was translated into simple Chinese using a professional translator as Chinese nationals constituted the majority of foreign nationals into Nigeria from high-risk countries. The Chinese version of the questionnaire was subsequently back translated to English by a postgraduate Chinese student to confirm its authenticity.

The questionnaire was pretested among 33 incoming international air travellers into Nnamdi Azikiwe International Airport (NAIA), Abuja before commencement of the study. The reliability of the tool was determined using Cronbach's alpha. A Cronbach's alpha of 0.75 was obtained for the willingness assessment scale while a Cronbach alpha of 0.72 was obtained for previous COVID-19 preventive practise scale. Those who participated in the pre-test did not participate in the main study.

Data quality assurance 
Skip logics and compulsory questions were employed to limit incomplete entries. In addition, a test question to screen out symptomatic incoming travellers was added to ensure data quality.

Data management and Analysis

Data was extracted from the google drive database into Microsoft Excel 2016 where it was cleaned including the removal of duplicate entries. Data analysis was performed using Microsoft Excel 2016 and Epi Info version 7.2

Willingness to comply with the recommended public health measures based on the prevailing recommendation by NCDC and WHO was assessed using a 4 vepoint Likert scale response which included 'not at all willing,' 'a little willing,' 'moderately willing,' 'very willing,' and 'extremely willing'. In addition to 'don't know' and 'refused' responses. The willingness to practise SARS-CoV-2 public health preventive measures recommended for asymptomatic POIs were assessed across five domains: Willingness to observe for symptoms of COVID-19 infection for 14 days after arrival; willingness to stay at home for 14 days after arrival, willingness to avoid contact with other people for 14 days after arrival, willingness to always properly cover nose and mouth if symptoms of SARS-CoV-2 develop within 14 days of arrival and their willingness to call approved national emergency numbers for COVID-19 if symptoms develop (NCDC's national COVID-19 hot-line). A respondent was categorised as willing to practise any of COVID-19 public health measures if he/she was very willing or extremely willing to practise any of COVID-19 public health measures within 14 days of arrival. Knowledge of COVID-19 was assessed using 6 questions with a minimum score of 0 and a maximum score of 6 . Those who scored 5 and above, out of 6 , were categorised as knowledgeable of SARS-CoV-2 infection and preventive practices. Their pre-arrival practise of recommended preventive measures against SARS-CoV-2 was assessed using 3 questions (frequent hand washing with soap and water/ use of hand sanitizers, avoiding persons with symptoms suggestive of acute respiratory tract infections and avoiding of face touching) on a 5-level Likert scale ranging from 'never' to 'always'. The scores were assigned as follows: 'Never' $=1$, 'Rarely' $=2$, 'Sometimes' $=3$, 'frequently' $=4$ and 'always' = 5 for the past 2 weeks. Self-rated health status was assessed using a ten-point scale from poor to excellent. ${ }^{26}$ Those who indicated 7 to 10 as their perceived health status were categorised as having a good self-rated health status. ${ }^{26}$

Univariate, bivariate (chi-square) and multivariable analysis of data was carried out. Odds ratios (ORs), confidence intervals and $P$-values were computed. Willingness to adhere to the individual public health measures within 14 days of arrival were the dependent variables while sociodemographic characteristics, knowledge of novel coronavirus symptoms and preventive practises, previous practise of COVID-19 preventive health measures, self-rated health status, perceived self-efficacy, perceived severity, perceived susceptibility and concern for self/family were the independent variables. For multivariable analysis, variables with a $P$-value of less than 0.2 in the bivariate analysis were entered into the multivariable logistic regression model using the backward approach. The level of significance was put at $5 \%$ for the adjusted OR.

Ethical consideration

Ethical approval was obtained from the National Health Research Ethics Committee, Abuja with approval number: NHREC/01/01/2007-10-/3/2020. Written informed consent was obtained from all respondents and confidentiality was maintained at all times. To ensure data security, access to the database was limited to only those involved in data analysis. At the end of the questionnaire, respondents were given links to NCDC, WHO and CDC websites on COVID-19 preventive measures and what to do if symptoms developed. Government approved national emergency numbers to call on development of symptoms suggestive of the novel coronavirus was also attached at the end of the questionnaire.

\section{Results}

Following data cleaning and removal of respondents who answered affirmative to having symptoms suggestive of COVID-19 based on the check question, only 500 respondents out of 591 respondents who participated in this study were analyzed. The mean age \pm standard deviation of the participants was 39.9 \pm 13.4 years with the highest proportion of the respondents -137 (27.4\%) being in the 35-44-year age group. Two hundred and eighty (56.0\%) were males and $463(92.6 \%)$ had tertiary education. Nationals belonging to 17 countries participated in this study with most being Nigerian nationals - 415 (83.0\%) followed by the Chinese -45 (9.0\%). A majority of the study participants $-427(85.4 \%)$ - were resident in Nigeria (Table 1$)$. 
Table 1

Characteristics of International In-coming Air travelers into Nigeria from countries with on-going Community Transmission of COVID-19, March 2020.

\begin{tabular}{|c|c|}
\hline \multirow[t]{2}{*}{ Variable } & Frequency (Percentage) \\
\hline & $\mathrm{n}=500$ \\
\hline \multicolumn{2}{|l|}{ Age group (years) } \\
\hline $18-24$ & $76(15.2)$ \\
\hline $25-34$ & $103(20.0)$ \\
\hline $35-44$ & $137(27.4)$ \\
\hline $45-54$ & $110(22.0)$ \\
\hline $55-64$ & $53(10.6)$ \\
\hline$\geq 65$ & $21(4.2)$ \\
\hline \multicolumn{2}{|l|}{ Sex } \\
\hline Male & $280(56.0)$ \\
\hline Female & $217(43.4)$ \\
\hline Prefer not to say & $3(0.6)$ \\
\hline \multicolumn{2}{|l|}{ Marital Status } \\
\hline Married & $305(61.0)$ \\
\hline Never married & 166 (33.2) \\
\hline Divorced & $16(3.2)$ \\
\hline Separated & $12(2.4)$ \\
\hline Widowed & $1(0.2)$ \\
\hline \multicolumn{2}{|l|}{ Nationality } \\
\hline Nigerian & $415(83.0)$ \\
\hline Chinese & $45(9.0)$ \\
\hline Others & $9(1.8)$ \\
\hline Italian & $7(1.4)$ \\
\hline British & $6(1.2)$ \\
\hline American & $5(1.0)$ \\
\hline German & $4(0.8)$ \\
\hline Indian & $4(0.8)$ \\
\hline South African & $3(0.6)$ \\
\hline French & $2(0.4)$ \\
\hline \multicolumn{2}{|l|}{ Education } \\
\hline Tertiary & $463(92.6)$ \\
\hline Secondary & $35(7.0)$ \\
\hline Primary & $2(0.4)$ \\
\hline \multicolumn{2}{|l|}{ Employment Status } \\
\hline Employed & $340(68.0)$ \\
\hline Not Employed & $160(32.0)$ \\
\hline \multicolumn{2}{|c|}{ Purpose of Stay in originating country } \\
\hline That is where I live/reside & $154(30.8)$ \\
\hline Business & $140(28.0)$ \\
\hline Social visit & $118(23.6)$ \\
\hline
\end{tabular}

*Other Nationals comprise of: Gambian (2), Angolan (1), Ghanaian - (1), Lebanese- (1), Burmese- (1), Dutch- (1), Norwegian- (1), Swedish - (1) 


\begin{tabular}{|c|c|}
\hline \multirow[t]{2}{*}{ Variable } & Frequency (Percentage) \\
\hline & $\mathrm{n}=\mathbf{5 0 0}$ \\
\hline Conference & $44(8.8)$ \\
\hline \multicolumn{2}{|l|}{ Nigeria as Place of Residence } \\
\hline Yes & $427(85.4)$ \\
\hline No, came for a visit & $73(14.6)$ \\
\hline \multicolumn{2}{|l|}{$\begin{array}{l}\text { Reason for visit to Nigeria if not place of residence } \\
(n=73)\end{array}$} \\
\hline Business & $24(32.9)$ \\
\hline Pleasure & $23(31.5)$ \\
\hline Both & $20(27.4)$ \\
\hline No response & $6(8.2)$ \\
\hline \multicolumn{2}{|l|}{ Airport of Entry } \\
\hline Murtala Muhammed International Airport, Lagos state & $378(75.6)$ \\
\hline Nnamdi Azikiwe International Airport, Abuja & $89(17.8)$ \\
\hline Mallam Aminu Kano International Airport, Kano state & $19(3.8)$ \\
\hline Port Harcourt International Airport, Rivers state & $14(2.8)$ \\
\hline
\end{tabular}

A total of $481(96.2 \%)$ incoming air travelers had an overall good knowledge of the novel coronavirus. However, concerning the mode of transmission of COVID-19, 43 (8.6\%) of the air travelers thought that it was not spread by sneeze/cough droplets while 25 ( $5.0 \%$ ) did not know the role of sneeze/cough in its spread. Concerning COVID-19 preventive practices in the last 4 weeks prior to arrival, $188(37.6 \%)$ had a good overall prior preventive practice (frequent handwashing/use of alcohol-based sanitizers, social distancing, avoidance of face touching and avoidance of crowded areas). Of all the in-coming travelers, 258 (51.6\%) admitted to sometimes/frequently/always of touching their face especially eyes, nose and mouth (Table 2). 


\begin{tabular}{|c|c|}
\hline Variable & $\begin{array}{l}\text { Frequency (Percentage) } \\
n=500\end{array}$ \\
\hline \multicolumn{2}{|c|}{ Frequent and thorough hand washing with soap and water or use of alcohol-based hand sanitizers } \\
\hline Always & $274(54.8)$ \\
\hline Frequently & $184(36.8)$ \\
\hline Never & $3(0.6)$ \\
\hline \multicolumn{2}{|c|}{ Keeping a distance of at least 1.5 meters or 5 feet from persons coughing or Sneezing } \\
\hline Always & $269(53.8)$ \\
\hline Never & $3(0.6)$ \\
\hline \multicolumn{2}{|c|}{ Touching of face especially eyes, nose and mouth } \\
\hline Always & $28(5.6)$ \\
\hline Frequently & $53(10.6)$ \\
\hline Sometimes & $177(35.4)$ \\
\hline Rarely & $169(33.8)$ \\
\hline Never & $73(14.6)$ \\
\hline Never & $17(3.4)$ \\
\hline
\end{tabular}

Within 14 days prior to arrival into Nigeria, only $1(0.2 \%)$ traveler admitted having been in contact with a confirmed case and only 3 ( $0.6 \%)$ admitted to have been to a health care facility where COVID-19 outbreak had been reported.

A majority of the travelers [497 (99.4\%)], self-rated their health status as good. Concerning their risk perception towards COVID-19, 474 (94.8 \%) thought that it was a very severe/severe disease. Majority of the travelers [426 (85.2\%)], were extremely concerned/very concerned/concerned about themselves/family members contracting the disease. However, $337(67.4 \%)$ thought that they had a small chance/ no chance at all of contracting the disease (Table 3 ). 
Table 3

Risk perceptions of International In-coming Air-travelers into Nigeria towards COVID-19, March 2020

\begin{tabular}{|ll|}
\hline Variable & Frequency (Percentage) \\
& $\mathrm{n}=500$ \\
\hline How severe do you think COVID-19 is? & $356(71.2)$ \\
\hline Very Severe & $118(23.6)$ \\
\hline Severe & $16(3.2)$ \\
\hline Not Sure & $8(1.6)$ \\
\hline Not Severe & $2(0.4)$ \\
\hline Not Severe at all & \\
\hline How concerned are you about yourself or family members getting COVID-19? & $282(56.4)$ \\
\hline Extremely Concerned & $75(15.0)$ \\
\hline Very Concerned & $69(13.8)$ \\
\hline Concerned & $40(8.0)$ \\
\hline Slightly concerned & $34(6.8)$ \\
\hline Not Concerned at all & \\
\hline What do you think are your chances of getting CoVID-19 infection & $8(1.6)$ \\
\hline Very Large chance & $9(1.8)$ \\
\hline Large chance & $146(29.2)$ \\
\hline Not sure & $150(30.0)$ \\
\hline Small chance & $187(37.4)$ \\
\hline No Chance at all & \\
\hline
\end{tabular}

Most of the POIs [415, (83.0\%)], were willing to comply with all 5 recommendations to prevent COVID-19. Of all the recommendations, the POIs were most willing to practice covering of nose and mouth if symptoms of cough/sneeze develop within 14 days of arrival [492 (98.4\%)] while avoiding contact with others was the practice that they were least willing to practice [278 (55.6\%)]. See Table 4. 
Variable

Frequency (Percentage)

$n=500$

Willingness to observe self for symptoms of COVID-19 for 14 days following arrival into Nigeria

Extremely Willing

338 (67.6)

Very Willing

136 (27.2)

Moderately Willing

$14(2.8)$

A little Willing

8 (1.6)

Not Willing at all

$4(0.8)$

Willingness to avoid contact with others for 14 days following arrival into Nigeria

Extremely Willing

$278(55.6)$

Very Willing

174 (34.8)

Moderately Willing

37 (7.4)

A little Willing

Not Willing at all

$5(1.0)$

Willingness to stay at home for 14 days following arrival into Nigeria

Extremely Willing

$330(66.0)$

Very Willing

140 (28.0)

Moderately Willing

$23(4.6)$

A little Willing

Not Willing at all

$1(0.2)$

Willingness to always properly cover nose and mouth if symptoms of coughing/sneezing develop within 14 days of arrival

Extremely Willing

375 (75.0)

Very Willing

117 (23.4)

Moderately Willing

$5(1.0)$

A little Willing

Not Willing at all

$0(0.0)$

Willingness to call national emergency numbers if symptoms of COVID-19 develop within 14 days of arrival

Extremely Willing

Very Willing

$132(26.4)$

Moderately Willing

$13(2.6)$

A little Willing

Not Willing at all

$0(0.0)$

As regards the concerns of the international air-travelers to practice the NCDC's recommendations for recent incoming air travelers for COVID-19, majority had no concerns as regards adhering to them (See figure 2). However, calling the national emergency numbers to notify the NCDC of development of symptoms suggestive of the novel coronavirus was the recommended behavior with the most concerns [134 (26.8\%)] while having to always properly cover their nose and mouth if they develop symptoms of coughing and sneezing [90 (18.0\%)] had the least concern (Figure 2).

Among travelers concerned about staying at home for 14 days after arrival, the need for food and drink [71 (53.4\%)] was their major concern about staying at home. Fear of what might be found was the major concern regarding self-observance for symptoms suggestive of COVID-19 [62 (46.3\%)]. See Table 5. The possibility of separation from loved ones was the most concern as regards calling the national emergency numbers to notify them of development of symptoms suggestive of COVID-19 [62 (46.3\%)]. While stigmatization/discrimination from others was the most concern as regards avoiding contact with others for 14 days following arrival [47 (42.3\%)]. In addition, forgetting to do so always was the most concern as regards always properly covering nose and mouth if symptoms suggestive of COVID-19 develop within 14 days of arrival [61 (67.7\%)]. See Table 5. 
Variable

Frequency

(Percentage)

Concerns about having to always properly cover my nose and mouth if symptoms of cough and sneezing develop $(n=90)$ *

I may forget to do so always

It is not convenient

$15(16.7)$

Other reasons ${ }^{* *}$

No particular reason but highly concerned

$9(10.0)$

Concerns about calling the National emergency COVID-19 numbers if symptoms of COVID-19 develop within 14 days of arrival (n $=134)^{*}$

I could be separated from my loved ones

I don't have the national emergency numbers

I may be discriminated against

My routine could be disrupted

$12(9.0)$

Concerns about staying at home for 14 days following their arrival $(n=133)$

I would need food and drink

I won't be able to care for my family

I may lose my job

Feelings of isolation

I may run out of essentials

8 (6.0)

No particular reason but very concerned

Other reasons $s^{\star * *}$

\section{Concerns about avoiding contact with others for 14 days following their arrival $(n=111)$ *}

Stigmatization/Discrimination from others

I won't be able to care for my family

$41(39.9)$

I may lose my job

8 (7.2)

Isolation

No particular reason, just extremely concerned

Other reasons $* * \star \star$

\section{Concerns about observing Self for COVID-19 for 14 days upon arrival $(n=111)$ *}

I am afraid of what I may find

$62(55.9)$

No particular reason, just extremely concerned

Other reasons $s^{\star \star \star \star \star}$

Feelings of isolation

Loneliness and lack of regular power supply

*This was the prevailing NCDC recommendation for in-coming international travelers on COVID-19 as at the time of the study. This was based on the WHO recommendations for COVID-19

**Other concerns about coverage of nose and mouth include: Being reported to NCDC (1), paying attention to carry what is needed (1), running out of tissues (2), stigmatization for using masks (1) and to avoid infecting others (1)

***Other concerns regarding staying at home include: Visa issues (1), Could slow down business (1), Health concerns (1)

****Other concerns for avoiding contact with others include: Hard to avoid people in a hotel (1), Lack of food (1), Could run out of essentials (1), People coming in and out of the house already (1)

***** Other concerns regarding observing self for symptoms include: Being responsible for symptoms due to recent travel (1), Concern for the health of others (1), A family man (1), constant cleaning of areas within the house and hands (1) 
POIs who perceived COVID-19 as very severe/severe were more likely to be extremely/very willing to stay at home compared with those who perceived it as less severe and this was statistically significant (AOR: $6.82,95 \% \mathrm{Cl}: 1.90-24.45$, Table 6). Those who came through MMIA and NAIA were more likely to be extremely/very willing stay at home for 14 days compared to those who came through MAKIA and PHIA (AOR: 5.35, 95\% Cl: 1.82 -15.73, Table 6). POIs who were extremely/highly confident in their ability to observe themselves for symptoms suggestive of COVID-19 were more likely to be to be extremely/very willing to stay at home compared to those who were not (AOR: $9.37,95 \%$ Cl: 3.38-25.97, Table 6). POls who were planning to stay beyond 2 weeks in Nigeria were extremely/highly willing to observe themselves for symptoms compared to those who were not (AOR: $5.85,95 \%$ Cl: $1.05-32.63$, Table 6). Those who were confident in their ability to observe themselves for symptoms suggestive of COVID-19 were more likely to be to be extremely/very willing to observe self for symptoms compared to those who were not (AOR: 5.16,95\% Cl 1.77-14.93, Table 6a). Concerning, willingness to avoid contact with others for 14 days following arrival into Nigeria, those with good prior preventive practice against COVID-19 were more likely to be extremely/very willing to avoid contact with others compared to those with poor prior preventive practice against COVID-19 (AOR: 3.40, 95\% Cl: 1.45-7.93, Table 7). Those who were confident in their ability to observe themselves for symptoms suggestive of COVID-19 were more likely to be to be extremely/very willing to avoid contact with others compared to those who were not (AOR: $4.69,95 \% \mathrm{Cl}$ : 1.97-11.15, Table 7). Concerning their willingness to call the national approved numbers for COVID-19 if symptoms develop within 14 days of arrival, those who were confident in their ability to observe themselves for symptoms suggestive of COVID-19 were more likely to be to be extremely/very willing to call the national approved numbers compared to those who were not (AOR: 4.47, 95\% Cl: 1.19-16.81, Table 8). 
Table 6

Predictors of willingness to comply with COVID-19 Preventive Measures by international air-travelers, Nigeria, March 2020

Independent Variable

Extremely/ Very willing to Stay at home for 14 days

Extremely/ Very willing to observe self for COVID-19 symptoms

Unadjusted Odds

Adjusted Odds

Unadjusted Odds

Adjusted Odds

COR $\quad 95 \% \mathrm{Cl}$

P- AOR $\quad 95 \% \mathrm{Cl}$

COR $\quad 95 \% \mathrm{Cl}$

P- AOR $95 \% \mathrm{Cl}$ value

\section{Age group (years)}

$<40$

$\geq 40$

1.00

$\begin{array}{llll}1.54 & 0.73 & 3.23 & 0.259\end{array}$

1.00

1.39

0.63

3.13

0.420

Gender

Female

Male

1.00

$\begin{array}{llll}0.85 & 0.40 & 1.81 & 0.677\end{array}$

1.00

Nationality

Nigerian

Non-Nigerian

$1.00-$

$\begin{array}{llll}1.35 & 0.46 & 3.98 & 0.581\end{array}$

0.581

$1.00-$

$\begin{array}{llll}0.89 & 0.20 & 3.88 & 0.874\end{array}$

$\begin{array}{llll}- & - & - & 1.00\end{array}$

Tertiary

1.00

Not Married

Married

$\begin{array}{llll}1.00 & - & - & - \\ 1.21 & 0.57 & 2.55 & 0.616\end{array}$

$\begin{array}{llll}- & - & - & 1.00\end{array}$

1.05

0.24

4.61

0.953

\section{Marital Status}

\section{Employed}

No

Yes

$\begin{array}{llllllll}1.00 & - & - & - & 1.00 & - & - & 1.00 \\ 1.68 & 0.80 & 3.55 & 0.170 & 0.83 & 0.35 & 1.94 & 2.62\end{array}$

2.23

$\begin{array}{ll}- & - \\ 1.00 & 4.96\end{array}$

$-$

1.00

Airport of Entry

MAKIA/PHIA

MMIA/NAIA

$\begin{array}{llllllll}1.00 & - & - & - & 1.00 & - & - & 1.00 \\ 5.20 & 2.04 & 13.23 & <0.001 & \mathbf{5 . 3 5} & \mathbf{1 . 8 2} & \mathbf{1 5 . 7 3} & 1.19\end{array}$

0.27

5.27

0.818

Nigeria as place of

Residence

No, came for a visit

Yes

$\begin{array}{lllllllll}1.00 & - & - & - & - & - & - & - & 1.00\end{array}$

$\begin{array}{llll}1.5 & 0.59 & 3.82 & 0.388\end{array}$

1.00

$\begin{array}{llll}- & - & - & 1.00\end{array}$

Duration of Stay

2 weeks and below

Beyond 2 weeks

1.00

1.00

$0.92-5.63$

$\begin{array}{llll}0.068 & 1.31 & 0.44 & 3.89\end{array}$

Living/Staying alone

\begin{tabular}{|c|c|c|c|c|c|c|c|c|c|c|c|c|c|}
\hline No & 1.00 & - & - & - & 1.00 & - & - & 1.00 & - & - & - & - & - \\
\hline Yes & 3.39 & 1.16 & 9.87 & 0.018 & 4.07 & 1.18 & 14.01 & 1.36 & 0.56 & 3.30 & 0.499 & - & - \\
\hline \multicolumn{14}{|c|}{ Knowledge of COVID-19 } \\
\hline Poor & 1.00 & - & - & - & - & - & - & 1.00 & - & - & - & - & - \\
\hline Good & 1.90 & 0.42 & 8.65 & 0.397 & - & - & - & 1.01 & 0.13 & 7.90 & 0.990 & - & - \\
\hline \multicolumn{14}{|l|}{$\begin{array}{l}\text { Perceived Severity of } \\
\text { COVID-19 }\end{array}$} \\
\hline Not Sure/ & 1.00 & - & - & - & 1.00 & - & - & 1.00 & - & - & - & 1.00 & - \\
\hline \multicolumn{14}{|l|}{ Not Severe/ } \\
\hline \multicolumn{14}{|l|}{ Not Severe at all } \\
\hline Very Severe/Severe & 4.28 & 1.49 & 12.28 & 0.004 & 6.82 & 1.90 & 24.45 & 2.56 & 0.72 & 9.14 & 0.135 & 2.43 & $0.62 \quad 9.61$ \\
\hline
\end{tabular}

Page $12 / 22$ 


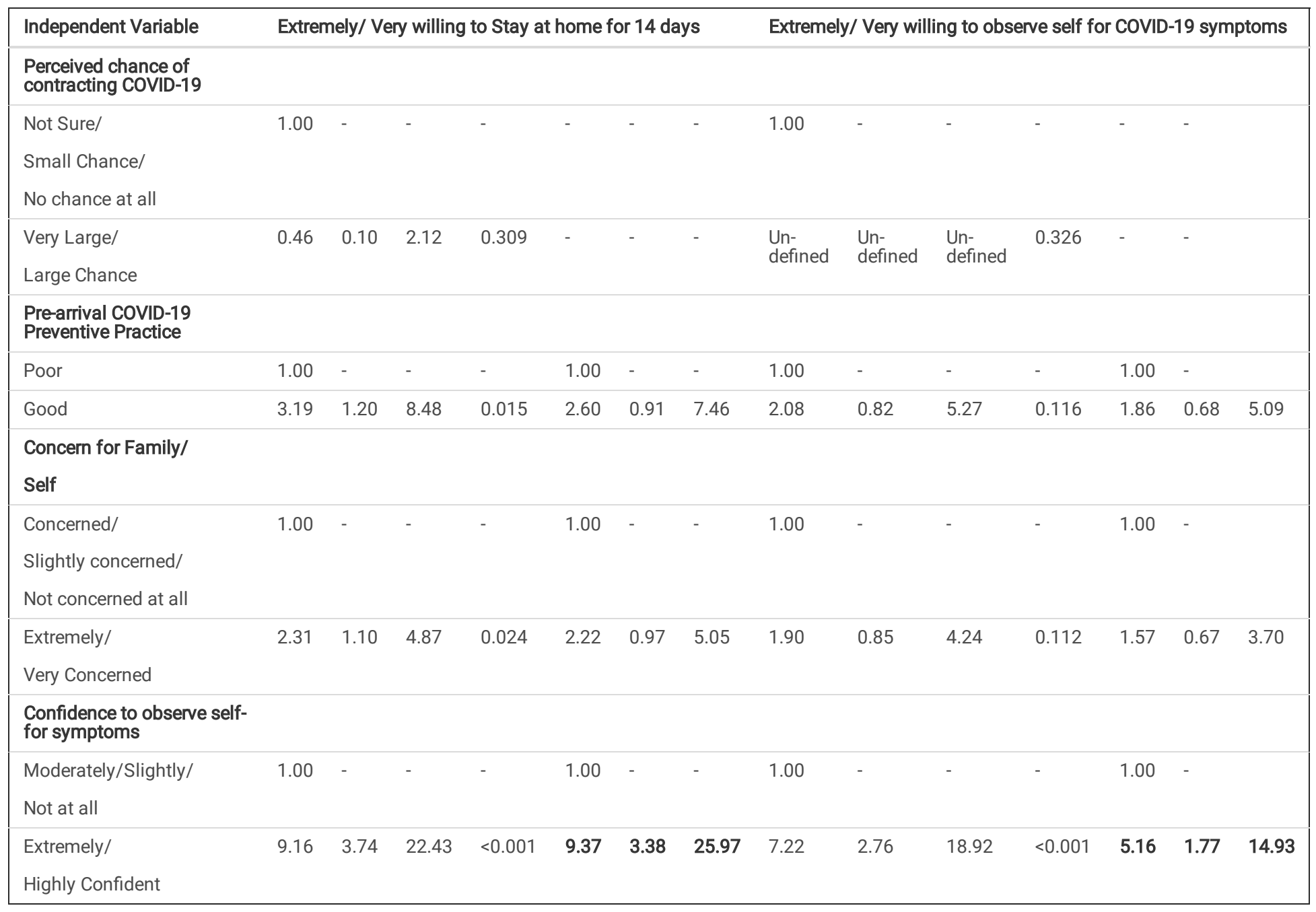


Table 7

Predictors of willingness to comply with COVID-19 Preventive Measures by international air-travelers, Nigeria, March 2020

\begin{tabular}{|c|c|c|c|c|c|c|c|c|c|c|c|c|c|c|}
\hline \multirow[t]{3}{*}{$\begin{array}{l}\text { Independent } \\
\text { Variable }\end{array}$} & \multicolumn{7}{|c|}{$\begin{array}{l}\text { Extremely/ Very willing to avoid contact with others for } \\
14 \text { days }\end{array}$} & \multicolumn{7}{|c|}{$\begin{array}{l}\text { Extremely/ Very willing to always properly cover mouth and nose if } \\
\text { symptoms of Sneezing/Coughing develop within } 14 \text { days of arrival }\end{array}$} \\
\hline & \multicolumn{4}{|c|}{ Unadjusted Odds } & \multicolumn{3}{|c|}{ Adjusted Odds } & \multicolumn{4}{|c|}{ Unadjusted Odds } & \multicolumn{3}{|c|}{ Adjusted Odds } \\
\hline & COR & $95 \% \mathrm{C}$ & & $\begin{array}{l}\mathrm{P} \text { - } \\
\text { value }\end{array}$ & AOR & $95 \% \mathrm{Cl}$ & & COR & $95 \% \mathrm{Cl}$ & & $\begin{array}{l}P- \\
\text { value }\end{array}$ & AOR & $95 \% \mathrm{C}$ & \\
\hline \multicolumn{15}{|l|}{ Age group (years) } \\
\hline$<40$ & 1.00 & - & - & - & - & - & - & 1.00 & - & - & - & 1.00 & - & - \\
\hline$\geq 40$ & 0.91 & 0.50 & 1.65 & 0.761 & - & - & - & 7.17 & 0.88 & 58.74 & 0.033 & 2.90 & 0.25 & 34.36 \\
\hline \multicolumn{15}{|l|}{ Gender } \\
\hline Female & 1.00 & - & - & - & - & - & - & 1.00 & - & - & - & - & - & - \\
\hline Male & 1.46 & 0.80 & 2.64 & 0.216 & - & - & - & 0.43 & 0.09 & 2.13 & 0.283 & - & - & - \\
\hline \multicolumn{15}{|l|}{ Nationality } \\
\hline Nigerian & 1.00 & - & - & - & - & - & - & 1.00 & - & - & - & 1.00 & - & - \\
\hline Non-Nigerian & 1.85 & 0.71 & 4.82 & 0.202 & - & - & - & $\begin{array}{l}\text { Un- } \\
\text { defined }\end{array}$ & $\begin{array}{l}\text { Un- } \\
\text { defined }\end{array}$ & $\begin{array}{l}\text { Un- } \\
\text { defined }\end{array}$ & 0.197 & 164533.06 & 0.00 & $>1.0 \mathrm{E} 1$ \\
\hline \multicolumn{15}{|l|}{ Educational Status } \\
\hline $\begin{array}{l}\text { Secondary } \\
\text { and below }\end{array}$ & 1.00 & - & - & - & - & - & - & 1.00 & - & - & - & 1.00 & - & - \\
\hline Tertiary & 1.53 & 0.57 & 4.12 & 0.401 & - & - & - & 4.35 & 0.85 & 22.37 & 0.055 & 5.06 & 0.72 & 35.71 \\
\hline \multicolumn{15}{|l|}{ Marital Status } \\
\hline Not Married & 1.00 & - & - & - & - & - & - & 1.00 & - & - & - & 1.00 & - & - \\
\hline Married & 1.37 & 0.75 & 2.48 & 0.307 & & & & 11.32 & 1.38 & 92.73 & 0.005 & 6.38 & 0.53 & 76.34 \\
\hline \multicolumn{15}{|l|}{ Employed } \\
\hline No & 1.00 & - & - & - & 1.00 & - & - & 1.00 & - & - & - & 1.00 & - & - \\
\hline Yes & 1.75 & 0.96 & 3.21 & 0.066 & 1.28 & 0.67 & 2.45 & 3.62 & 0.86 & 15.36 & 0.062 & 0.56 & 0.11 & 4.59 \\
\hline \multicolumn{15}{|l|}{ Airport of Entry } \\
\hline MAKIA/PHIA & 1.00 & - & - & - & 1.00 & - & - & 1.00 & - & - & - & 1.00 & - & - \\
\hline MMIA/NAIA & 2.80 & 1.14 & 6.84 & 0.019 & 2.47 & 0.94 & 6.50 & 4.96 & 0.96 & 25.58 & 0.035 & 6.24 & 0.86 & 45.23 \\
\hline \multicolumn{15}{|l|}{$\begin{array}{l}\text { Nigeria as place of } \\
\text { Residence }\end{array}$} \\
\hline No, came for a visit & 1.00 & - & - & - & - & - & - & 1.00 & - & - & - & - & - & - \\
\hline Yes & 1.40 & 0.65 & 3.03 & 0.392 & - & - & - & 0.00 & $\begin{array}{l}\text { Un- } \\
\text { defined }\end{array}$ & $\begin{array}{l}\text { Un- } \\
\text { defined }\end{array}$ & 0.238 & - & - & - \\
\hline \multicolumn{15}{|l|}{ Duration of Stay } \\
\hline 2 weeks and below & 1.00 & - & - & - & - & - & - & 1.00 & - & - & - & - & - & - \\
\hline Beyond 2 weeks & 2.44 & 0.67 & 8.99 & 0.165 & 2.55 & 0.58 & 11.31 & 0.00 & $\begin{array}{l}\text { Un- } \\
\text { defined }\end{array}$ & $\begin{array}{l}\text { Un- } \\
\text { defined }\end{array}$ & 0.616 & - & - & - \\
\hline \multicolumn{15}{|l|}{$\begin{array}{l}\text { Living/Staying } \\
\text { alone }\end{array}$} \\
\hline No & 1.00 & - & - & - & - & - & - & 1.00 & - & - & - & - & - & - \\
\hline Yes & 1.54 & 0.78 & 3.04 & 0.215 & - & - & - & 1.49 & 0.30 & 7.45 & 0.628 & - & - & - \\
\hline \multicolumn{15}{|l|}{$\begin{array}{l}\text { Knowledge of } \\
\text { COVID-19 }\end{array}$} \\
\hline Poor & 1.00 & - & - & - & - & - & - & 1.00 & - & - & - & - & - & - \\
\hline Good & 1.82 & 0.51 & 6.47 & 0.350 & - & - & - & 0.00 & $\begin{array}{l}\text { Un- } \\
\text { defined }\end{array}$ & $\begin{array}{l}\text { Un- } \\
\text { defined }\end{array}$ & 0.571 & - & - & - \\
\hline
\end{tabular}




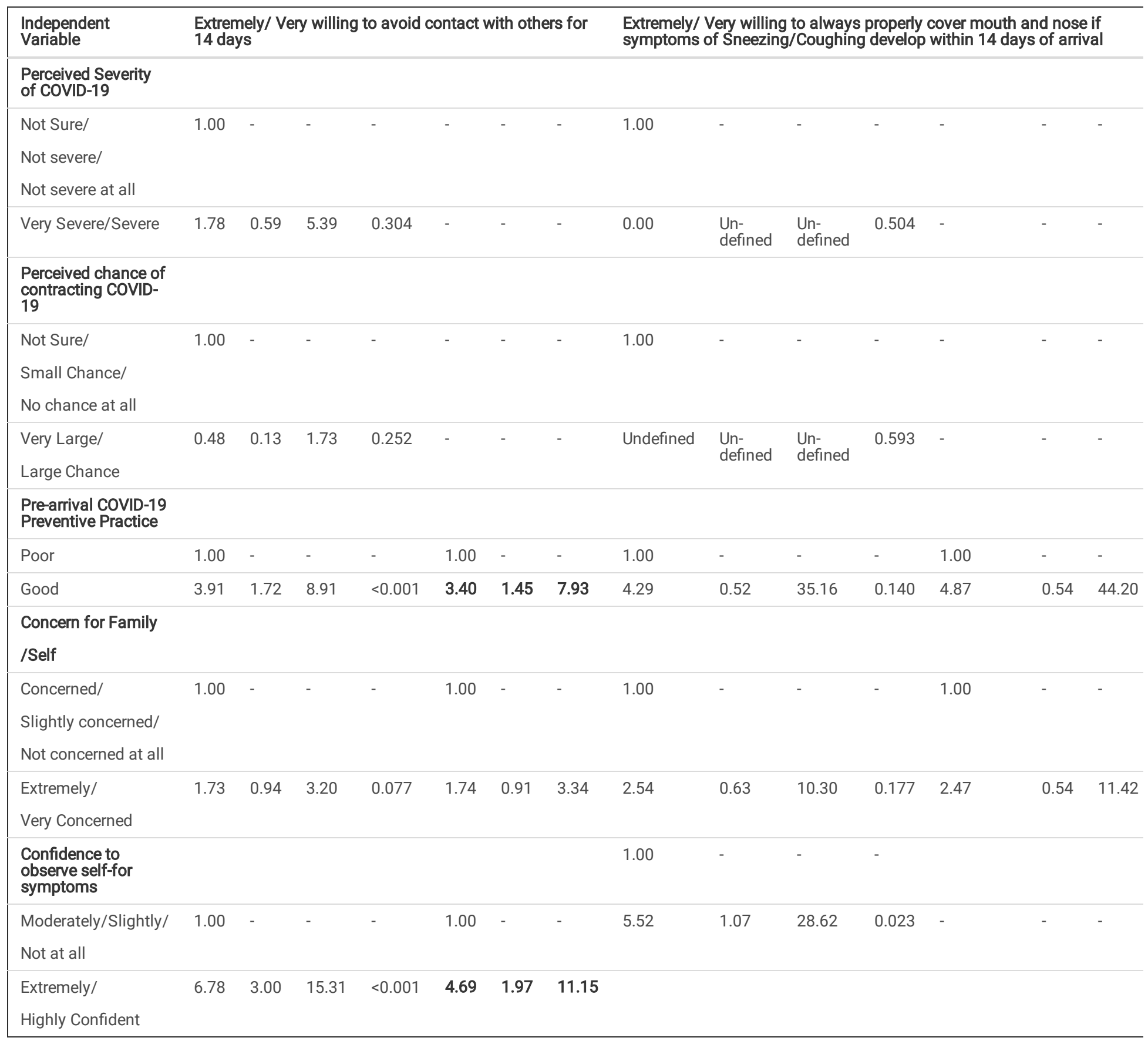


Table 8

Predictors of willingness to comply with COVID-19 Preventive Measures by international air-travelers, Nigeria, March 2020

\begin{tabular}{|c|c|c|c|c|c|c|c|}
\hline \multirow[t]{3}{*}{ Independent Variable } & \multicolumn{7}{|c|}{$\begin{array}{l}\text { Extremely/ Very willing to call national COVID-19 emergency numbers within } 14 \text { days of arrival if symptoms } \\
\text { develop }\end{array}$} \\
\hline & \multicolumn{4}{|c|}{ Unadjusted Odds } & \multicolumn{3}{|c|}{ Adjusted Odds } \\
\hline & OR & $95 \% \mathrm{Cl}$ & & P-value & OR & $95 \% \mathrm{Cl}$ & \\
\hline \multicolumn{8}{|l|}{ Age group (years) } \\
\hline$<40$ & 1.00 & - & - & - & 1.00 & - & - \\
\hline$\geq 40$ & 4.15 & 1.16 & 14.90 & 0.018 & 3.50 & 0.87 & 14.07 \\
\hline \multicolumn{8}{|l|}{ Gender } \\
\hline Female & 1.00 & - & - & - & 1.00 & - & - \\
\hline Male & 2.66 & 0.90 & 7.89 & 0.068 & 1.88 & 0.59 & 6.07 \\
\hline \multicolumn{8}{|l|}{ Nationality } \\
\hline Nigerian & 1.00 & - & - & - & - & - & - \\
\hline Non-Nigerian & 1.34 & 0.30 & 6.06 & 0.701 & - & - & - \\
\hline \multicolumn{8}{|l|}{ Educational Status } \\
\hline Secondary and & 1.00 & - & - & - & - & - & - \\
\hline \multicolumn{8}{|l|}{ below } \\
\hline Tertiary/Post- & 0.89 & 0.11 & 6.97 & 0.912 & - & - & - \\
\hline \multicolumn{8}{|l|}{ secondary } \\
\hline \multicolumn{8}{|l|}{ Marital Status } \\
\hline Not Married & 1.00 & - & - & - & - & - & - \\
\hline Married & 2.41 & 0.85 & 6.88 & 0.09 & 1.27 & 0.35 & 4.62 \\
\hline \multicolumn{8}{|l|}{ Employed } \\
\hline No & 1.00 & - & - & - & 1.00 & - & - \\
\hline Yes & 2.50 & 0.89 & 7.03 & 0.072 & 1.10 & 0.33 & 3.68 \\
\hline \multicolumn{8}{|l|}{ Airport of Entry } \\
\hline MAKIA/PHIA & 1.00 & - & - & - & - & - & - \\
\hline MMIA/NAIA & 2.25 & 0.49 & 10.43 & 0.286 & - & - & - \\
\hline \multicolumn{8}{|c|}{ Nigeria as place of Residence } \\
\hline No, Came for a visit & 1.00 & - & - & - & - & - & - \\
\hline Yes & 1.48 & 0.41 & 5.39 & 0.548 & - & - & - \\
\hline \multicolumn{8}{|l|}{ Duration of Stay } \\
\hline 2 weeks and below & 1.00 & - & - & - & - & - & - \\
\hline Beyond 2 weeks & 0.00 & Undefined & Undefined & 0.489 & - & - & - \\
\hline \multicolumn{8}{|l|}{ Living/Staying alone } \\
\hline No & 1.00 & - & - & - & 1.00 & - & - \\
\hline Yes & 3.29 & 0.73 & 14.76 & 0.100 & 3.37 & 0.67 & 16.94 \\
\hline \multicolumn{8}{|l|}{ Knowledge } \\
\hline \multicolumn{8}{|l|}{ of COVID-19 } \\
\hline Poor & 1.00 & - & - & - & - & - & - \\
\hline Good & 0.00 & Undefined & Undefined & 0.435 & - & - & - \\
\hline
\end{tabular}




\begin{tabular}{|c|c|c|c|c|c|c|c|}
\hline \multirow{2}{*}{$\begin{array}{l}\text { Independent Variable } \\
\text { Not Sure/ }\end{array}$} & \multicolumn{7}{|c|}{$\begin{array}{l}\text { Extremely/ Very willing to call national COVID-19 emergency numbers within } 14 \text { days of arrival if symptoms } \\
\text { develop }\end{array}$} \\
\hline & 1.00 & - & - & - & - & - & - \\
\hline \multicolumn{8}{|l|}{ Not severe/ } \\
\hline \multicolumn{8}{|l|}{ Not severe at all } \\
\hline Very Severe/ Severe & 2.96 & 0.63 & 13.84 & 0.150 & 3.86 & 0.72 & 20.75 \\
\hline \multicolumn{8}{|c|}{$\begin{array}{l}\text { Perceived chance of contracting COVID- } \\
19\end{array}$} \\
\hline Not Sure/ & 1.00 & - & - & - & - & - & - \\
\hline \multicolumn{8}{|l|}{ Small Chance/ } \\
\hline \multicolumn{8}{|l|}{ No chance at all } \\
\hline Very large/ & 0.48 & 0.06 & 3.86 & 0.478 & - & - & - \\
\hline \multicolumn{8}{|l|}{ large chance } \\
\hline \multirow{2}{*}{\multicolumn{8}{|c|}{$\begin{array}{l}\text { Pre-arrival } \\
\text { COVID-19 Preventive Practice }\end{array}$}} \\
\hline & & & & & & & \\
\hline Poor & 1.00 & - & - & - & 1.00 & - & - \\
\hline Good & 4.04 & 0.90 & 18.12 & 0.049 & 3.48 & 0.73 & 16.58 \\
\hline \multicolumn{8}{|l|}{$\begin{array}{l}\text { Concern } \\
\text { for Family/Self }\end{array}$} \\
\hline Concerned/ & 1.00 & - & - & - & - & - & - \\
\hline \multicolumn{8}{|l|}{ Slightly/ } \\
\hline \multicolumn{8}{|l|}{ Not concerned at all } \\
\hline Extremely/ & 0.91 & 0.28 & 2.89 & 0.866 & - & - & - \\
\hline \multicolumn{8}{|l|}{ Very Concerned } \\
\hline \multicolumn{8}{|l|}{$\begin{array}{l}\text { Confidence } \\
\text { to observe } \\
\text { self-for symptoms }\end{array}$} \\
\hline Moderately/ & 1.00 & - & - & - & 1.00 & - & - \\
\hline \multirow{2}{*}{\multicolumn{8}{|c|}{$\begin{array}{l}\text { Slightly/ } \\
\text { Not at all }\end{array}$}} \\
\hline & & & & & & & \\
\hline Extremely/ & 6.42 & 1.91 & 21.54 & $<0.001$ & 4.47 & 1.19 & 16.81 \\
\hline Highly Confident & & & & & & & \\
\hline
\end{tabular}

\section{Discussion}

The finding that most of the study participants were willing to comply with all the Nigeria Centre for Disease Control's COVID-19 prevention recommendations for incoming travelers is encouraging. The high willingness to comply with COVID-19 preventive measures in this study may largely be due to increase in risk communication and community engagement globally in line with the WHO strategy of risk communication and community engagement (RCCE) which could afford most individuals the opportunity to have some information that would improve their health seeking behavior. ${ }^{27}$ This could also be a reflection of the respondents' high education level which on its own could influence the willingness of the individuals to comply with disease preventive measures including COVID-19. However, close to half of the respondents were not willing to avoid contact with others. This may be because socialization is part of all societies as man naturally is a social being. ${ }^{28}$ This finding presents additional basis for the relevant authorities to further engage the POls and the general public on the role of physical contact in COVID-19 transmission and the importance of avoiding contacts not just for the symptomatic individuals but also the apparently healthy individuals.

The good knowledge of COVID-19 demonstrated by the majority of the participants in this study may have been due to increased public awareness campaign on COVID-19 globally especially as the respondents were coming from countries already affected by the pandemic with on-going risk communication activities. This finding is in keeping with that of a cross-sectional study in China which found a good knowledge of COVID-19 among the respondents. ${ }^{29}$ Another study done in the United States and the United Kingdom among the general public showed a good knowledge about COVID-19. ${ }^{30}$ 
Our finding that only a few respondents had a good overall prior preventive practice against COVID-19 (e.g., frequent hand washing and use of alcohol-based hand sanitizers, social distancing, and avoidance of face touching and crowded areas) has great implication in public health as lack of compliance to preventive measures worsens the pandemic. This is even more worrisome finding this among international traveler who have the potential of exporting the disease. The non-satisfactory proportion for overall prior preventive practice against COVID-19 observed in this study, may be because COVID-19 is a novel disease hence, requiring more health education to influence behavioral change in terms of adhering to good preventive practices for COVID-19. This suggests possible gaps in risk communication on COVID-19 prevention from the originating countries. This is opposed to the finding in an earlier study conducted in China ${ }^{29}$ and to a similar study done among health workers in China by M. Zhou et $a^{31}$

The perception of COVID-19 as a severe disease by a majority of the respondents is in keeping with a cross-sectional study that assessed the risk perception of COVID-19 around the world. ${ }^{12}$ It is worthy of note that COVID-19 is highly transmissible and has led to so many mortalities globally according to WHO reports. This may explain the finding in this study. The finding that participants who perceived COVID-19 as severe or very severe were more likely to be extremely or very willing to stay at home for 14 days, compared with those who perceived it as less severe is similar to the result of a study in the US where perceived infection risk was associated with protective behaviors. ${ }^{32}$ Respondents who came through the Lagos and Abuja airports were observed to be more likely to be willing to practice the preventive measures like staying at home for 14 days, avoiding contact with others, proper covering of nose and mouth which may suggest a difference in the risk communication activities at these international airports compared to the rest in the country. This is probably as a result of the increased federal attention given to MMIA given that it had the bulk of international air travelers into the country as well as the fact that the recording of the country's index case of COVID-19 came in through it. In addition, the location of NAIA at the country's capital where the FMOH, NCDC offices are located, could have resulted in increased attention to surveillance at NAIA POE. Age not being a significant influencer of willingness was surprising in this study as risky behavior among younger adults is not uncommon. ${ }^{33}$ In addition, to the fact that bad outcome, including death, is commoner among older people across the globe ${ }^{34,35}$.

A high confidence in the ability to observe self for symptoms of COVID-19 (self- efficacy) was a prominent predictor of the POIs willingness to comply with COVID-19 preventive measures across four of the five domains assessed (willingness to stay at home, willingness to observe self for symptoms suggestive of COVID-19, avoiding of contact with others and calling of national emergency numbers on COVID-19 within 14 days of arrival). This was not surprising as selfefficacy is a known determinant of health behavior and behavioral change including future health-related behavior. ${ }^{36}$ Hence there is a need to build their confidence through intensive public enlightenment and engagement of high risk international travelers upon arrival. This study also calls for the need to intensify monitoring of the POls during their first 14 days of arrival through calls and home visits because a failure to monitor for symptoms and act promptly could lead to local transmission of the virus and community spread especially for those who may be unwilling to comply with public health measures against COVID-19.

The findings of this study may be limited by desirability bias where respondents may give the response that they think the researcher wants to hear. Hence, an introductory note buttressing the need for sincerity of responses was added to limit that. In addition, findings of this study may have been limited by misclassification bias (symptomatic POls vs non-symptomatic POIs) as some travellers may not have volunteered correct information about COVID-19 symptoms upon arrival at the airport, hence the addition of certain questions in the instrument to control for that (presence of suggestive symptoms in respondent). Also, the evolution in current public health measures against COVID-19 for international air travellers such as wearing of face masks to cover nose and mouth to prevent COVID-19 spread even when asymptomatic, not just covering of nose and mouth when sneezing and coughing, 37,38 and COVID-19 testing during international travel (pre-departure and upon arrival) may limit the current applicability of our study findings. ${ }^{39}$ However, the robust representativeness of the study makes its result worth considering and could help policy-makers design evidenced-based risk communication strategies especially at international airports prior to departure and upon arrival as this also has the potential to prevent in flight transmission of COVID-19 for air travelers ${ }^{40} \mathrm{In}$ addition, the novel nature of this disease and a lack of similar studies limited a robust comparison of findings with other similar studies.

\section{Conclusion}

International air travelers play a significant role in the spread or containment of the COVID-19 pandemic. We found that perceived severity of COVID-19, duration of stay in country of arrival, airport of entry and self-efficacy towards observing self for COVID-19 symptoms were significant factors influencing the willingness of international air travelers to comply to COVID-19 preventive measures. This study, therefore, reinforces the need for good and sustained risk communication and behavior change interventions on COVID- 19 especially their self-efficacy in all countries particularly among international air travelers (whether entry or exit) as COVID-19 is an ongoing global pandemic.

We recommend that international travelers be willing to adhere to all public health measures against COVID-19 as this will limit international spread of the virus particularly new variants. We also recommend that risk communication activities for COVID-19 for international travellers especially targeting their selfefficacy should be intensified by relevant stakeholders as this plays a crucial role on influencing the willingness of international incoming travellers to follow COVID-19 preventive measures and recommendations on arrival. We also recommend further studies to assess the practice of COVID-19 related preventive measures and outcome among international air travellers as well as studies to determine the relationship between international air travelers' willingness to comply with COVID-19 preventive measure and their actual compliance. We believe that this will better guide policy makers on interventions to help contain the pandemic, especially in this period of gradual re-opening of international flights around the world, Nigeria inclusive.

\section{Abbreviations}


COVID-19 Coronavirus Disease 2019

NCDC Nigeria Centre for Disease Control

PHEIC Public Health Emergency of International Concern.

POE Point of Entry

PHS Port Health Services

POI Persons of Interest

RCCE Risk Communication and Community Engagement

WHO World Health Organization

\section{Declarations}

\section{Ethics approval and consent to participate}

Ethical approval was obtained from the National Health Research Ethics Committee, Abuja with approval number: NHREC/01/01/2007-10-/3/2020. Written informed consent was obtained from all respondents and confidentiality was maintained at all times

\section{Consent for publication}

Not applicable

\section{Availability of data and materials}

All the data associated with this work is available from the corresponding author on reasonable request

\section{Competing interests}

The authors have no competing interest to declare

\section{Funding}

The authors did not receive any particular funding support for this work

\section{AUTHORS CONTRIBUTION}

Conception and Design of the study

ISU,CDU, MSB, COA,UCO, AAO,CSO,EB, KE, ALI, MA, JO, PN, and CI

Acquisition of Data

ISU,CDU, MSB, COA, IHZ, CSO,PIO, AM, and CPE

Analysis and Interpretation of Data

ISU,CDU, AAO,andEB

Drafting the article/revising it critically for important intellectual content

ISU,CDU, MSB, COA,IHZ, UCO, AAO,CSO, PIO, AM, CPE,EB, KE, ALI, MA, JO, PN, and CI

Final approval of the version to be submitted:

All authors read and approved the final version for submission.

AKNOWLEDGEMENT:

We acknowledge the Port Health Services (PHS) Federal Ministry of Health, Nigeria, Nigeria Centre for Disease Control (NCDC), the Nigeria Field Epidemiology and Laboratory Training Program (NFELTP) and African Field Epidemiology Network (AFENET) for support rendered. We thank all International incoming 
travelers who agreed to participate in this study. Your participation is highly appreciated.

\section{References}

1. Wells CR, Sah P, Moghadas SM, Pandey A, Shoukat A, Wang Y, et al. Impact of international travel and border control measures on the global spread of the novel 2019 coronavirus outbreak. Proc Natl Acad Sci U S A [Internet]. 2020 Mar 31 [cited 2020 Jul 8];117(13):7504-9. Available from:

https://github.com/WellsRC/Coronavirus-2019.

2. Wilson M, Chen L. Travellers give wings to novel coronavirus (2019-nCoV) [Internet]. Vol. 27, J Travel Med. 2020 [cited 2020 Jul 7]. p. taaa015. Available from: https://www.ncbi.nlm.nih.gov/pmc/articles/PMC7107561/

3. Lau JTF, Yang X, Tsui HY, Pang E. SARS related preventive and risk behaviours practised by Hong Kong-mainland China cross border travellers during the outbreak of the SARS epidemic in Hong Kong. J Epidemiol Community Heal. 2004;58.:988-996.

4. Bogoch I, Watts A, Thomas-Bachli A, Huber C, Kraemer M, Khan K. Potential for global spread of a novel coronavirus from China. JTravMed [Internet]. 2020;27(2):taaa011. Available from: https://doi.org/ 10.1093/jtm/taaa011.

5. Rodríguez-Morales AJ, MacGregor K, Kanagarajah S, Patel D, Schlagenhauf P. Going global - Travel and the 2019 novel coronavirus. Vol. 33 , Travel Medicine and Infectious Disease. Elsevier USA; 2020.

6. World Health Organization. Coronavirus disease 2019 (COVID-19) Situation Report-42 [Internet]. Geneva,Switzerland; 2020. Available from: https://www.who.int/docs/default-source/coronaviruse/20200302-sitrep-42-covid-19.pdf?sfvrsn=d863e045_2

7. Nigeria Centre for Disease Control. 29th February 2020/Public Health Advisory to Nigerians on novel Coronavirus(\#4) [Internet]. Nigeria Centre for Disease Control. 2020 [cited 2020 Mar 1]. Available from: https://ncdc.gov.ng/news/234/29th-february-2020\%7C-public-health-advisory-to-nigerians-on-novelcoronavirus- $\% 28 \% 234 \% 29$

8. World Health Organization. Coronavirus disease (COVID-19) advice for the public [Internet]. World Health Organization,. Geneva,Switzerland; 2020 [cited 2020 Feb 22]. Available from: https://www.who.int/emergencies/diseases/novel-coronavirus-2019/advice-for-public

9. World Health Organization. WHO Director-General's opening remarks at the media briefing on COVID-19 - 11 March 2020 [Internet]. World Health Organization. 2020 [cited 2020 Jul 8]. Available from: https://www.who.int/dg/speeches/detail/who-director-general-s-opening-remarks-at-the-mediabriefing-on-covid-19-11-march-2020

10. Champion VL, Skinner CSC. The Health Belief Model. In: Glanz K, Rimer B, Viswanath K, editors. Health Behavior and Health Education: Theory, Research, and Practice. 4th ed. San Francisco, CA: Jossey Bass; 2008. p. 45-65.

11. Rimer BK, Glanz K. Theory at a glance: A guide for health promotion practice. 2nd ed. U.S. Department of Health and Human services National Institutes of Health; 2005.

12. Dryhurst S, Schneider CR, Kerr J, Freeman ALJ, Recchia G, van der Bles AM, et al. Risk perceptions of COVID-19 around the world. J Risk Res. 2020;

13. Taylor M, Raphael B, Barr M, Agho K, Stevens G, Jorm L. Public health measures during an anticipated influenza pandemic: Factors influencing willingness to comply [Internet]. Vol. 2, Risk Manag Healthc Policy. 2009 [cited 2020 Feb 21]. p. 9-20. Available from: https://www.ncbi.nlm.nih.gov/pmc/articles/PMC3270909/

14. Jefferson T, Del Mar C, Dooley L, Ferroni E, Al-Ansary L, Bawazeer G et al. Physical interventions to interrupt or reduce the spread of respiratory viruses: systematic review. BMJ [Internet]. 2009;339:b3675-b3675. Available from: http://www.bmj.com/cgi/doi/10.1136/bmj.b3675

15. Leung GM, Lam T-H, Ho L-M, Ho S-Y, Chan BHY, Wong IOL, et al. The impact of community psychological responses on outbreak control for severe acute respiratory syndrome in Hong Kong. J Epidemiol Community Health. 2003 Nov;57(11):857-63.

16. Lau JT, Kim JH, Tsui HY, Griffiths S. Anticipated and current preventive behaviors in response to an anticipated human-to-human H5N1 epidemic in the Hong Kong Chinese general population. BMC Infect Dis. 2007 Dec;7(1):18.

17. Di Giuseppe G, Abbate R, Albano L, Marinelli P, Angelillo IF. A survey of knowledge, attitudes and practices towards avian influenza in an adult population of Italy. BMC Infect Dis. 2008 Dec;8(1):36.

18. Lau J, Kim J, Tsui H, Griffiths S. Perceptions Related to Bird-to-Human Avian Influenza, Influenza Vaccination, and Use of Face Mask. Infection [Internet] 2008;36(5):434-43. Available from: http://link.springer.com/10.1007/s15010-008-7277-y

19. Federal Airports Authority of Nigeria. December 2015 Annual Report-Federal Airports Authority. 2015.

20. Matazu A. China-Nigeria trade vlume increased by \$15.3bn in 2018. Daily Trust [Internet]. 2019 Apr 19; Available from: https://www.dailytrust.com.ng/china-nigeria-trade-volume-increased-by-15-3bn-in-2018.html

21. Nigeria Centre for Disease Control. 15th March 2020|Public Health Advisory to Nigerians on Coronavirus Disease (\#5) [Internet]. 2020 [cited 2020 Mar 16]. Available from: https://ncdc.gov.ng/news/240/15th-march-2020\%7C-public-health-advisory-to-nigerians-on-coronavirus-disease-\%28\%235\%29

22. Nigeria Centre for Disease Control. Surveillance Case definitions for COVID-19 (Version 2) [Internet]. 2020 [cited 2020 Mar 3]. Available from: https://ncdc.gov.ng/themes/common/docs/protocols/168_1582983645.pdf

23. Centers for Disease Control and Prevention. Coronavirus Disease 2019 (COVID-19) FAQ for Travellers [Internet]. Centers for Disease Control and Prevention. 2020 [cited 2020 Feb 15]. Available from: https://www.cdc.gov/coronavirus/2019-ncov/travelers/faqs.html

24. Centers for Disease Control and Prevention. Coronavirus Disease 2019 (COVID-19) [Internet]. Centers for Disease Control and Prevention. 2020. Available from: https://www.cdc.gov/coronavirus/2019-ncov/php/risk-assessment.html

25. Kish L. Survey Sampling. New York: John Wiley and Sons, Inc.; 1965. 78-94 p. 
26. Ware J, Snoww K, MA K, BG G. SF36 Health Survey: Manual and Interpretation Guide. [Internet]. Lincoln, Rl: Quality Metric, Inc;; 1993 [cited 2020 Aug 16]. 6.8. Available from: https://www.researchgate.net/publication/247503121_SF36_Health_Survey_Manual_and_Interpretation_Guide

27. World Health Organization. 2019 Novel Coronavirus (2019-nCoV): Strategic Preparadeness and Response Plan [Internet]. Geneva, Switzerland: WHO Press; 2020. 12 p. Available from: https://www.who.int/publications/i/item/strategic-preparedness-and-response-plan-for-the-new-coronavirus

28. Whyte W, Marshall L. Man as A Social Animal. In: Social Sciences Foundation Course Team, editor. Understanding Society [Internet]. Palgrave, London; 1970. p. 80-106. Available from: https://link.springer.com/chapter/10.1007/978-1-349-15392-3_5

29. Zhong BL, Luo W, Li HM, Zhang QQ, Liu XG, Li WT, et al. Knowledge, attitudes, and practices towards CoVID-19 among chinese residents during the rapid rise period of the COVID-19 outbreak: A quick online cross-sectional survey. Int J Biol Sci [Internet]. 2020 [cited 2020 Jul 7];16(10):1745-52. Available from: /pmc/articles/PMC7098034/?report=abstract

30. Geldsetzer P. Knowledge and Perceptions of COVID-19 Among the General Public in the United States and the United Kingdom: A Cross-sectional Online Survey. Vol. 173, Annals of Internal Medicine. American College of Physicians; 2020. p. 157-60.

31. Zhou M, Tang F, Wang Y, Nie H, Zhang L, You G, et al. Knowledge, attitude and practice regarding COVID-19 among health care workers in Henan, China. Vol. 105, Journal of Hospital Infection. Elsevier BV; 2020. p. 183-7.

32. De Bruin WB, Parker AM, Fischhoff B. Individual differences in adult decision-making competence. J Pers Soc Psychol. 2007 May;92(5):938-56.

33. Rolison J, Hanoch Y, Wood S, Liu P-J. Risk-Taking Differences Across the Adult Life Span: A Question of Age and Domain. journals Gerontol Ser B [Internet]. 2014;69(6):870-880. Available from: https://academic.oup.com/psychsocgerontology/article/69/6/870/545646

34. World Health Organization. Q\&A: Older people and COVID-19 [Internet]. World Health Organization,. 2020 [cited 2020 Aug 10]. Available from: https://www.who.int/news-room/q-a-detail/q-a-on-on-covid-19-for-older-people

35. Mueller A, McNamara M, Sinclair D. Why does COVID-19 disproportionately affect older people? Albany NY Aging [Internet]. 2020;12(10):9959-81. Available from: https://www.ncbi.nlm.nih.gov/pmc/articles/PMC7288963/

36. Holloway A, Watson HE. Role of self-efficacy and behaviour change. Int J Nurs Pract [Internet]. 2002 [cited 2020 Aug 16];8(2):106-15. Available from: https://pubmed.ncbi.nlm.nih.gov/11993577/

37. Liang M, Gao L, Cheng C, Zhou Q, Uy J, Heiner K, et al. Efficacy of face mask in preventing respiratory virus transmission: A systematic review and metaanalysis. Travel Med Infect Dis. 2020;36:101751.

38. World Health Organization. Masks use in the context of COVID-19 [Internet]. [cited 2021 Apr 18]. Available from: https://www.who.int/publications/item/advice-on-the-use-of-masks-in-the-community-during-home-care-and-in-healthcare-settings-in-the-context-of-thenovel-coronavirus-(2019-ncov)-outbreak

39. Nigeria Centre for Disease Control. Public Health Advisory on COVID-19 [Internet]. 2021 [cited 2021 Apr 18]. Available from: https://covid19.ncdc.gov.ng/advisory/

40. Chen J, He H, Cheng W, Liu Y, Sun Z, Chai C, et al. Potential transmission of SARS-CoV-2 on a flight from Singapore to Hangzhou, China: An epidemiological investigation. Travel Med Infect Dis. 2020;36:101816.

\section{Figures}




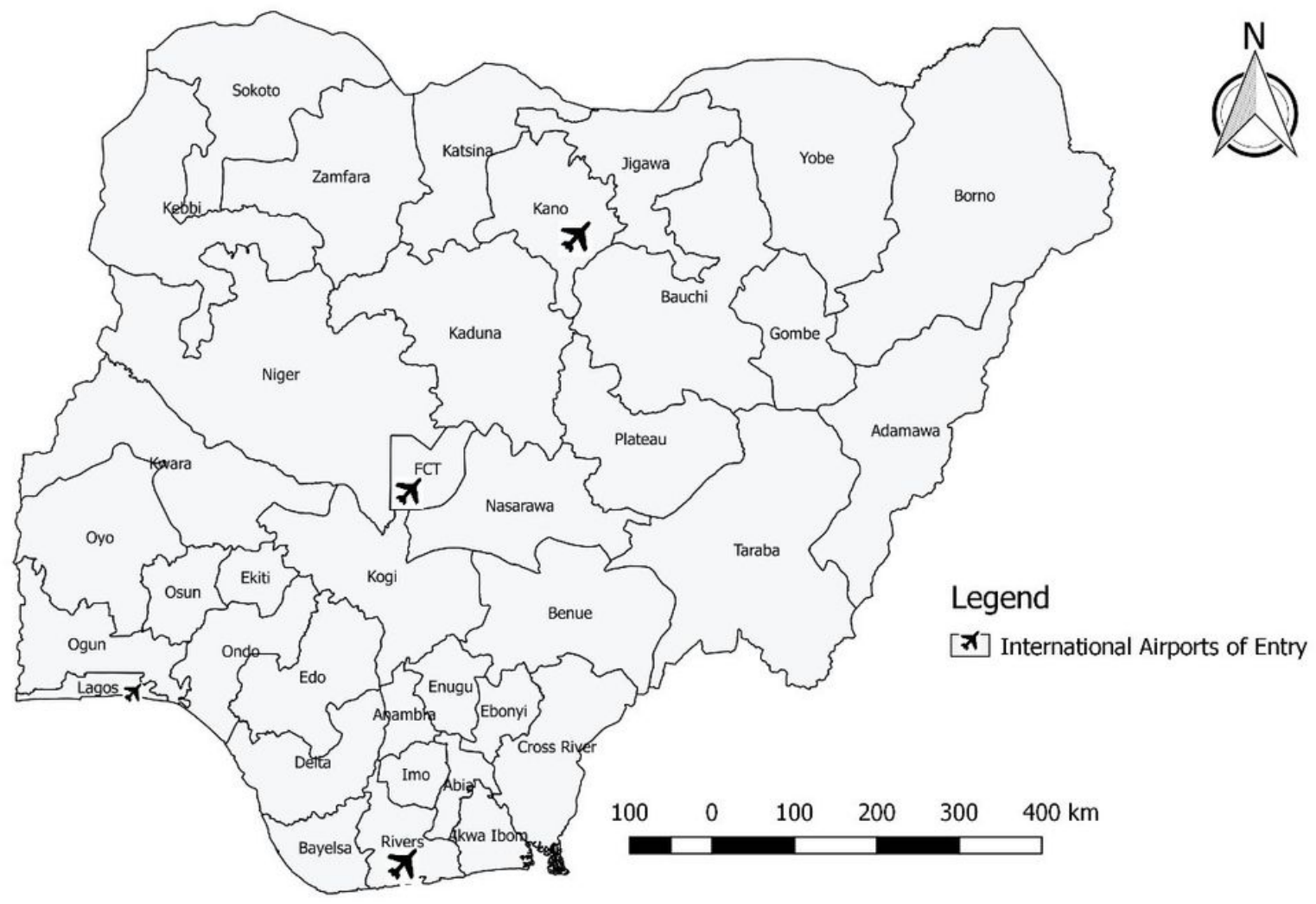

\section{Figure 1}

Locations of the designated international Airports of entry for COVID-19 POE Surveillance, Nigeria, March 2020 (This image was created using a free QGIS 2.18.5 software)

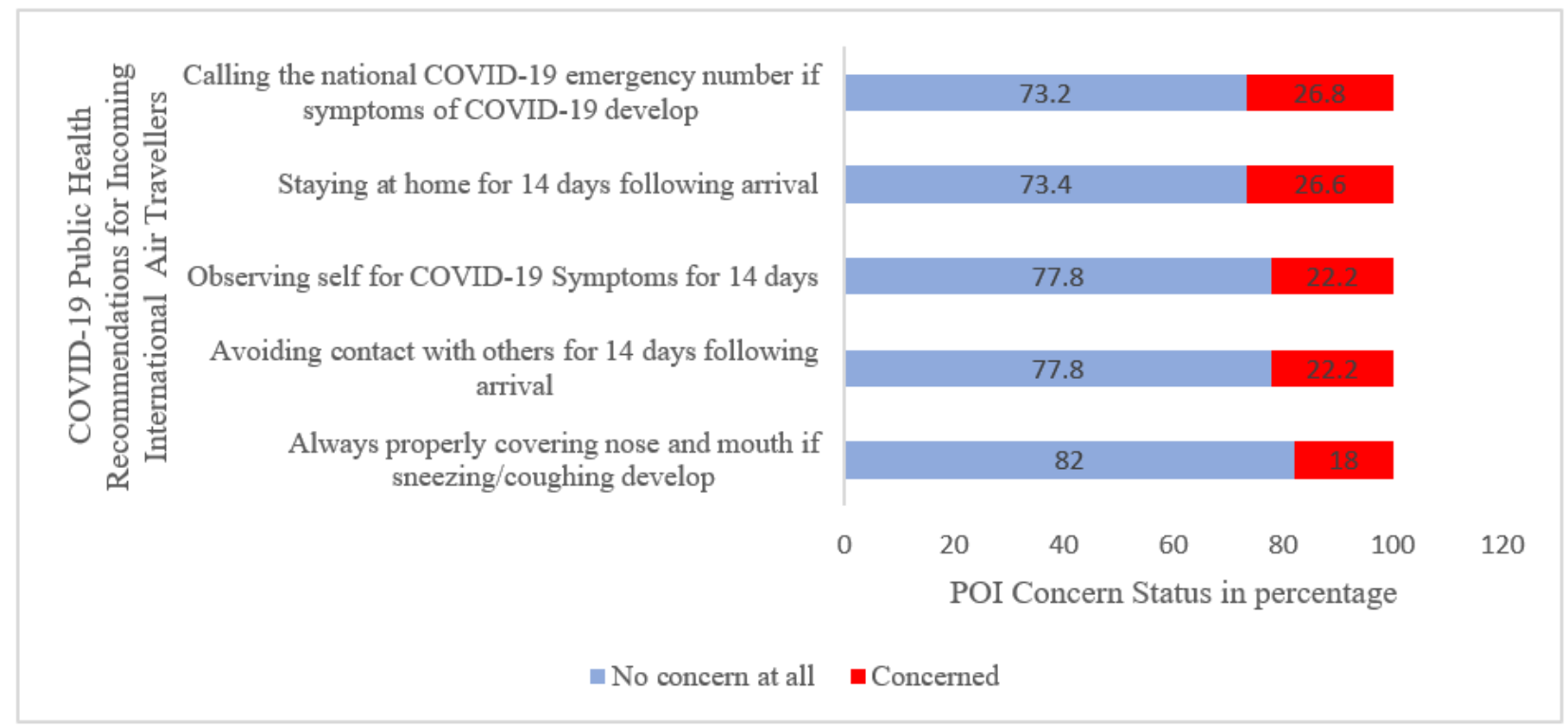

Figure 2

International Air travellers' Concerns regarding Nigeria's COVID-19 Public Health recommendation for In-coming Travellers, March 2020

Page 22/22 